\title{
Investigation of the Potential for Eucalyptus Leaf Oil Extraction Industry in Sri Lanka
}

\author{
S.A.Y. Medhavi ${ }^{1 *}$, S.M.C.U.P. Subasinghe ${ }^{1}$, D.S. Hettiarachchi ${ }^{2}$ \\ ${ }^{1}$ Department of Forestry and Environmental Science, University of Sri Jayewardenepura, Sri Lanka \\ ${ }^{2}$ Wescorp Group of Companies, 26, Coulson Way, Canning Vale, WA, Australia \\ *yasika0117@gmail.com
}

\begin{abstract}
Eucalyptus oil is a product of secondary metabolism of trees which is extracted mostly by its leaves. It holds a long history of use against respiratory infections due to its antibacterial, antifungal and antiviral properties and also acts as a fragrance in perfumes and as a flavouring agent in certain food items.
\end{abstract}

A survey was conducted in the first phase of this study with the Customs Department to identify the existing market potential for Eucalyptus oil in Sri Lanka. Results revealed that the export is far below in compared with the imports. Although a few local oil extractors are present, their production is highly insufficient to meet even the local market demand, hence most of the Eucalyptus oil demand is fulfilled by importing large quantities from Australia, China, India and United Kingdom. Therefore if the optimum conditions are identified, commercial level extraction of Eucalyptus oil will be an ideal opportunity of earning a significant income for both government and private sectors because they manage nearly 32,000 ha of Eucalyptus plantations in Sri Lanka. This will create much benefit, especially for the owners of Eucalyptus plantations grown above 1,500 m from mean sea level, because harvesting of those plantations have been banned.

Hydro and steam distillation are the only two methods used in Eucalyptus leaf oil extraction in commercial scale. Therefore the second phase of the study was designed to identify the best distillation method and required optimum physical conditions in Eucalyptus leaf oil extraction. Fresh leaves were collected from the middle of the canopy of a young $E$. microcorys plantation at Demodara and those were air dried under shade. Both steam and hydro distillation methods were conducted parallely for $250 \mathrm{~g}$ of leaves, using a small-scale distillation apparatus for 3 hours. The effect of the particle size of the leaves (full leaf and $4.0,2.0,0.2 \mathrm{~cm})$ and leaf to water ratio $(1: 4,1: 6$ and 1:8 (w/v)) were examined. Altogether 24 different treatments were used with three replicates. According to one-way ANOVA, 16 different combinations of the tested variables had significantly higher oil yields. Among them there were 11 steam distillation methods and five hydro distillation methods. However, the best average oil content was yielded by the hydro distillation, used with leaves cut into 4.0 $\mathrm{cm}$ and with 1:4 leaf water ratio.

Keywords: Eucalyptus leaf oil, Distillation, Eucalyptus microcorys, Oil yield 